\title{
Optimal Fiscal Policy in the Uzawa-Lucas Model with CES Production
}

\author{
MANUEL A. GÓMEZ, ANTONIO SARMIENTO ESCALONA, J. ANTONIO SEIJAS*
}

\begin{abstract}
A bstract
This paper devises an endogenous growth model with human capital in the UzawaLucas framework in which the average human capital has a positive external effect on the goods sector. Unlike previous works, this paper assumes that output is produced with a CES technology and analyzes the existence, uniqueness, and stability of equilibrium. Also, a fiscal policy is devised that is capable of providing the required incentives to optimize the competitive equilibrium. In order to correct the market failure caused by the externality, the authors introduce a subsidy to human capital and analyze how it can be financed in an optimal way. Some simulation results are presented.(JEL O41, E62); Int'l Advances in Econ. Res., 10(3): pp. 202-214, Aug. 04. (ㄷ) All Rights Reserved
\end{abstract}

\section{Introduction}

The Uzawa-Lucas model [Uzawa, 1965; Lucas, 1988] has been the subject of active research in the past decade [Caballé and Santos, 1993; Chamley, 1993; Mulligan and Sala-i-Martín, 1993; Bond et al., 1996; Ladrón-de-Guevara et al., 1999; Gómez, 2003, 2004]. In the absence of externalities, the market equilibrium coincides with the optimal growth path and, therefore, the government intervention is not justified. Gómez [2004] points out that the mere presence of externalities does not provide an incontrovertible rationale for government intervention. It further shows that a sector-specific externality associated with human capital in the goods sector does not cause a market failure since the competitive equilibrium is optimal. However, other types of externalities may provoke a market failure. In his seminal paper, Lucas [1988] considers a case where average human capital has an external effect in the goods sector. The presence of such an externality causes the fraction of time devoted to human capital accumulation to be inferior to the optimal. The government could then intervene to induce the agents to devote more time to education, correcting the market failure, and, as a consequence, improving welfare.

García-Castrillo and Sanso [2000] and Gómez [2003] derive fiscal policies that optimize the decentralized equilibrium in the Uzawa-Lucas model with externalities á la Lucas. In these papers, output is produced with a Cobb-Douglas technology. Since the Cobb-Douglas specification, with physical and human capital serving as inputs, is consistent with one of Kaldor's stylized facts of growth - that the share of income accruing to capital and labor are relatively constant over time - most researchers have not questioned its use to study growth and development. Nevertheless, some researchers have expressed doubts about the CobbDouglas orthodoxy. Solow [1958] pointed out that Kaldor's stylized fact is not that factor shares have been absolutely constant, as the Cobb-Douglas specification literally implies, but rather that these shares have been relatively constant over the short period of time for which

${ }^{*}$ University of A Coruña-Spain 
there is available data. Solow noted that slight departures from a Cobb-Douglas specification, in the form of a constant-elasticity-of-substitution (CES) production technology with an elasticity of substitution that is only slightly different from unity, results in small trends in factor shares of income that are consistent with the observed relative stability of these shares over longer periods of time. The implications of the neoclassical growth model with a CES production technology were further spelled out by Pitchford [1960] and resurrected by other authors [Jones and Manuelli, 1990; Rebelo, 1991; Duffy and Papageorgiu, 2000]. Hence, this paper considers that a CES technology is more adequate than a Cobb-Douglas production function to study the economic development process.

The purpose of this paper is to develop an endogenous growth model with human capital in the Uzawa-Lucas framework with externalities a la Lucas, when output is produced with a CES technology. First, the study analyzes the existence, uniqueness, and stability of equilibrium. Then, a fiscal policy capable of providing the required incentives to attain optimal competitive equilibrium is devised. Physical capital income should be free of taxation. The optimal fiscal policy requires the use of a time-varying subsidy rate to the stock of human capital, which can be financed by means of a lump-sum tax combined with a constant tax on labor income, at least in the transitory phase. However, lump-sum taxation is not needed to balance the government budget in the steady state.

The study also performs a simulation analysis to gain some insight on the behavior of the subsidy and tax rates. As expected, as the externality increases the subsidy rate, the government's size increases steadily to correct the market failure provoked by the average human capital in the production of goods. The tax rate on labor income also increases as the externality increases to finance the higher subsidy required to correct the externality.

The remainder of this paper is organized as follows. The next sections describe the decentralized economy and the centrally planned economy. Then, the optimal fiscal policy is analyzed. The following section presents some simulation results. Finally, the conclusion follows.

\section{The M arket Economy}

Consider an economy populated by a large number of identical, infinitely-lived representative agents who derive utility from the consumption of a private consumption good, $c$. For simplicity, this paper assumes that population is constant and normalized to 1 . The intertemporal utility derived by the agent is represented by the isoelastic utility function

$$
W=\int_{0}^{\infty} e^{-p t}\left(c^{1-\sigma}-1\right) /(1-\sigma) d t \quad \rho>0, \sigma>0
$$

where $\rho$ is the rate of time preference and $\sigma$ is the inverse of the elasticity of intertemporal substitution. The endowment of time is normalized as a constant flow of one unit per period. A fraction of time, $u$, is allocated to work and $1-u$ to learning. Following Lucas [1988], it is assumed that human capital, $h$, is accumulated according to the dynamic equation

$$
\dot{h}=\delta(1-u) h \quad \delta>0 .
$$

Note that this specification coincides with that considered by García Castrillo [2000] and Gómez [2003].

The rate of return on physical capital is denoted as $r$ and the wage rate as $w$. The government taxes physical capital income at the rate $\tau_{k}$ and labor income at $\tau_{w}$, and also imposes a lump-sump tax, $T$. Government subsidizes the stock of human capital at rate $s$. In the absence of depreciation of physical capital, the household's budget constraint is then 


$$
\dot{k}=\left(1-\tau_{k}\right) r k+\left(1-\tau_{w}\right) w u h-c-T+\pi+s h \quad,
$$

where $\pi$ denotes positive profits. The representative agent maximizes (1) subject to the constraints (2) and (3).

Output, $y$, is produced with a CES technology by using as inputs the stocks of physical, $k$, human capital, $h$, the individual's supply as labor, $u$, and the average human capital of the economy, $h_{a}$, according to:

$$
y=A k^{1-\alpha}\left(a(u h)^{\beta}+(1-a) h_{a}^{\beta}\right)^{\alpha / \beta} \quad A>0,0<\alpha<1, \beta>-1,0<a<1 .
$$

This specification assumes that production is subject to a decreasing returns-to-scale at the private level and a constant returns-to-scale at the social level. When $\beta$ tends to zero, the production function (4) becomes the Cobb-Douglas production function:

$$
y=A k^{1-\alpha}(u h)^{\alpha a} h_{a}^{\alpha(1-a)} \quad,
$$

so that the Cobb-Douglas technology used by García Castrillo [2000] and Gómez [2003] is a particular case of (4). In the market solution, the atomistic agents treat $h_{a}$ as given. By symmetry, the value of $h_{a}$ is equal to $h$ in equilibrium. Because of the externality, the competitive solution differs from the planner's solution.

Profit maximization by competitive firms implies that labor and capital are used to the point at which marginal product equates marginal cost:

$$
\begin{gathered}
r=(1-\alpha) y / k \\
w=\frac{\alpha a(u h)^{\beta-1} y}{a(u h)^{\beta}+(1-a) h_{a}^{\beta}} .
\end{gathered}
$$

Since the production function exhibits decreasing returns-to-scale at the private level, the competitive firm earns positive profits:

$$
\pi=y-r k-w u h \quad .
$$

This paper assumes that these profits are distributed back to households as dividends. As Benhabib and Nishimura [1998] point out, unless the number of firms is fixed, positive profits should be combined with a fixed entry cost to determine the number of firms along the equilibrium. Assuming that the government runs a balanced-budget:

$$
\tau_{k} r k+\tau_{w} w u h+T=s h \quad .
$$

Hereafter, let $g_{z}=\frac{\dot{z}}{z}$ denote the growth rate of the variable $z$. Solving the agent's utility maximization problem, the dynamics of the decentralized economy can be expressed in terms of variables that are constant in the steady state, defining $x=k / h$ and $q=c / k$. Then, the following system is obtained (see Appendix A for details on the derivation):

$$
g_{q}=\left(\left(1-\tau_{k}\right)(1-\alpha)-\sigma\right) A x^{-\alpha}\left(1-a+a u^{\beta}\right)^{\alpha / \beta} / \sigma+q-\rho / \sigma \quad,
$$




$$
\begin{gathered}
g_{x}=A x^{-\alpha}\left(1-a+a u^{\beta}\right)^{\alpha / \beta}-q-\delta(1-u) \\
g_{u}=\frac{\left(1-a+a u^{\beta}\right)}{(\alpha-1) a u^{\beta}+(\beta-1)(1-a)} *\left(\frac{s \delta u^{1-\beta}\left(1-a+a u^{\beta}\right)^{1-\alpha / \beta}}{\left(1-\tau_{w}\right) a \alpha A x^{1-\alpha}}+\right. \\
\left.\tau_{k}(1-\alpha) A x^{-\alpha}\left(1-a+a u^{\beta}\right)^{\alpha / \beta}-(1-\alpha) q-\frac{\dot{\tau}_{w}}{1-\tau_{w}}+(1-\alpha) \delta u+\delta \alpha\right)
\end{gathered}
$$

\section{The Centrally Planned Economy}

The central planner possesses complete information and chooses all quantities directly, taking all the relevant information into account. Taking $h_{a}=h$, the central planner maximizes (1) subject to (2) and

$$
\dot{k}=A k^{1-\alpha}\left(a(u h)^{\beta}+(1-a) h^{\beta}\right)^{\alpha / \beta}-c .
$$

The first-order conditions of the planner's problem are shown in Appendix B. In the same manner as in the case of the market economy, the following system of equations which characterizes the dynamics of the centrally planned economy are obtained:

$$
\begin{gathered}
g_{q}=A x^{-\alpha}\left(1-a+a u^{\beta}\right)^{\alpha / \beta}(1-\alpha-\sigma) / \sigma+q-\rho / \sigma \quad, \\
g_{x}=A x^{-\alpha}\left(1-a+a u^{\beta}\right)^{\alpha / \beta}-q-\delta(1-u), \\
g_{u}=\frac{u^{-\beta}\left(1-a+a u^{\beta}\right)\left(u \delta-a u \delta+a u^{\beta}(q(-1+\alpha)+(u+\alpha-u \alpha) \delta)\right)}{a\left(-1+a+\beta-a \beta+a u^{\beta}(-1+\alpha)\right)} .
\end{gathered}
$$

If we denote $z=y / k$, the growth rate of $z$ can be easily obtained as

$$
g_{z}=\alpha \delta(1-u)-\alpha(z-q)-\alpha \frac{u \delta-a u \delta+a u^{\beta}(q(-1+\alpha)+(u+\alpha-u \alpha) \delta)}{-1+a+\beta-a \beta+a(-1+\alpha) u^{\beta}} \quad .
$$

The system (9) can be expressed equivalently in terms of $q, z$, and $u$, as

$$
\begin{gathered}
g_{q}=(1-\alpha) z / \sigma-z+q-\rho / \sigma \\
g_{u}=-\frac{u^{-\beta}\left(1-a+a u^{\beta}\right)\left(u \delta-a u \delta+a u^{\beta}(q(-1+\alpha)+(u+\alpha-u \alpha) \delta)\right)}{a\left(-1+a+\beta-a \beta+a u^{\beta}(-1+\alpha)\right)} \\
g_{x}=z-q-\delta(1-u) .
\end{gathered}
$$

The next proposition states a necessary and sufficient condition for the existence of a feasible interior steady state equilibrium. 


\section{Proposition 1}

The centrally-planned economy has a unique positive steady state equilibrium with a positive long-run growth rate:

$$
\begin{gathered}
q^{*}=\left(\rho+\left(1-u^{*}\right) \delta(\alpha+\sigma-1)\right) /(1-\alpha) \\
z^{*}=\left(\rho+\delta \sigma\left(1-u^{*}\right)\right) /(1-\alpha)
\end{gathered}
$$

where $u^{*}$ is given implicitly by the solution to the equation

$$
(-1+a) \delta u^{* 1-\beta}+a\left(\rho+\delta\left(\sigma-1-\sigma u^{*}\right)\right)=0,
$$

where the steady state growth rate of output, consumption, and the stocks of physical and human capital equals

$$
\gamma_{y}^{*}=\gamma_{c}^{*}=\gamma_{k}^{*}=\gamma_{h}^{*}=\delta\left(1-u^{*}\right)
$$

if and only if

$$
\delta(1-\sigma)<\rho<\delta / a .
$$

Proposition 2

The steady state of the optimal-growth problem in the Uzawa-Lucas model when average human capital has an external effect on productivity is locally saddle-path stable. See Appendix B for further proof.

\section{The Optimal Fiscal Policy}

The key question that is addressed in this section is what fiscal policy is capable of making the decentralized economy replicate the first-best optimum attainable by a central planner and described by system (9). First, note that equations (7b) and (9b), which describe the dynamics of $x$ in the decentralized and centrally planned economies, respectively, coincide. Comparing equations (7a) and (9a), one can see that the decentralized economy will fully replicate the dynamic time path of $q$ in the centrally planned economy only if the tax rate on physical capital income is zero, that is, $\tau_{k}=0$. Equating the right hand sides of equations $(7 \mathrm{c})$ and $(9 \mathrm{c})$, after substituting $\tau_{k}$ for 0 , and considering that $\tau_{w}$ is constant (that is, $\dot{\tau}_{w}=0$ ), the following expression for the subsidy rate to the stock of human capital is obtained:

$$
s=\left(1-\tau_{w}\right)(1-a) \alpha(y / h) /\left(1-a+a u^{\beta}\right),
$$

or equivalently,

$$
s=A\left(1-\tau_{w}\right)(1-a) \alpha x^{1-\alpha}\left(1-a+a u^{\beta}\right)^{(\alpha-\beta) / \beta} \quad .
$$

The optimal subsidy rate given by equation (15) is feasible, since for a given constant value of the tax rate of the labor income, $\tau_{w}$, the size of the government, that is, the ratio between the amount of subsidy to the stock of human capital and output is less than 1 :

$$
g=s h / y=\left(1-\tau_{w}\right)(1-a) \alpha /\left(1-a+a u^{\beta}\right)<1 .
$$


The optimal policy requires resorting to lump-sum taxation to balance the government budget, at least during the transition to the steady state. The optimal value of the lump-sum tax can be obtained from (15) and (6) as:

$$
\frac{T}{y}=\alpha\left(\left(\frac{(1-a)}{1-a+a u^{\beta}}\right)-\tau_{w}\right) \quad .
$$

Such a policy is feasible since the ratio of lump-sum taxes (or transfers, if $T$ is negative) to output can be readily shown to be less than one in absolute value.

$$
|T / y|<1
$$

Once the steady state is reached, the subsidy to the stock of human capital can be fully financed by means of a constant tax rate on labor income:

$$
\tau_{w}=(1-a) /\left(1-a+a u^{* \beta}\right),
$$

which fulfills the condition $0<\tau_{w}<1$. Thus, we can state the following proposition.

Proposition 2

The decentralized economy can attain the first-best equilibrium solution if physical capital income is not taxed and the stock of human capital is subsidized at a (time-varying) rate $s=\left(1-\tau_{w}\right)(1-a) \alpha(y / h) /\left(1-a+a u^{\beta}\right)$. The subsidy can be financed by taxing labor income at a constant rate $\tau_{w}$ and equating the ratio of lump-sum taxes (or transfers) to output to $T / y=\alpha\left((1-a) /\left(1-a+a u^{\beta}\right)-\tau_{w}\right)$. Lump-sum taxation is not required to balance the government budget in the steady state, in which case labor income should be taxed at a (constant) rate $\tau_{w}=(1-a) /\left(1-a+a u^{* \beta}\right)$

It should be noted that the result that the optimal growth path can be attained by instituting a subsidy to the stock of human capital is consistent with the Pigouvian tax intuition that a subsidy directed at the source of a positive externality will correct the market failure. As is well known, a tax on labor income at a constant rate is non-distortionary in the Uzawa-Lucas model (see Lucas [1990]) and is equivalent to a lump-sum tax. Hence, the subsidy is set so as to correct the market failure provoked by the external effects and, in the steady state, it can be financed by a non-distortionary tax on labor income.

\section{Simulation R esults}

This section presents some simulation results to gain insight on the size of the optimal subsidy and the tax rate on income. The model is calibrated to the U.S. economy. The parameter $A$ is simply normalized to unity. Following Lucas [1990] and Pecorino [1994], the elasticity of intertemporal substitution, $1 / \sigma$, is chosen as 0.5 , and the rate of time preference, $\rho$, as 0.034 . As usual, the elasticity of physical capital in production, $1-\alpha$, is set at $1 / 3$.

Figure 1 displays the steady-state optimal values of the subsidy to human capital, $s$, given by (15), the tax on labor income, $\tau_{w}$, given by (17), and the size of the government, $g$, given by (16). Several values of the parameter $\beta$, below and above zero, which cover a reasonable range have been chosen. The value of $a$ is then varied from 0.5 to 1 , which seems to cover the relevant range, for the externality (note that the size of the externality is given by $1-a$ ). In each simulation exercise, the productivity parameter in the production of human capital, $\delta$, is set so that the model replicates the post-war U.S. long-run growth rate of 1.5 percent [Lucas, 1990 and Pecorino, 1994]. 


\section{FIGURE 1}

Optimal Steady State Fiscal Policy

Elasticity of substitution, $\beta=-0.5$

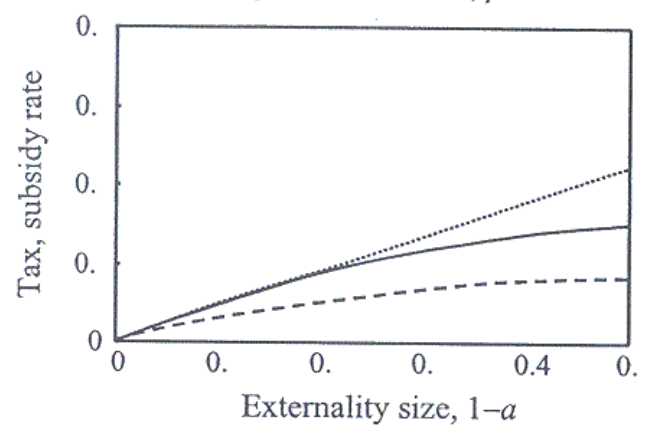

Elasticity of substitution, $\beta=0$
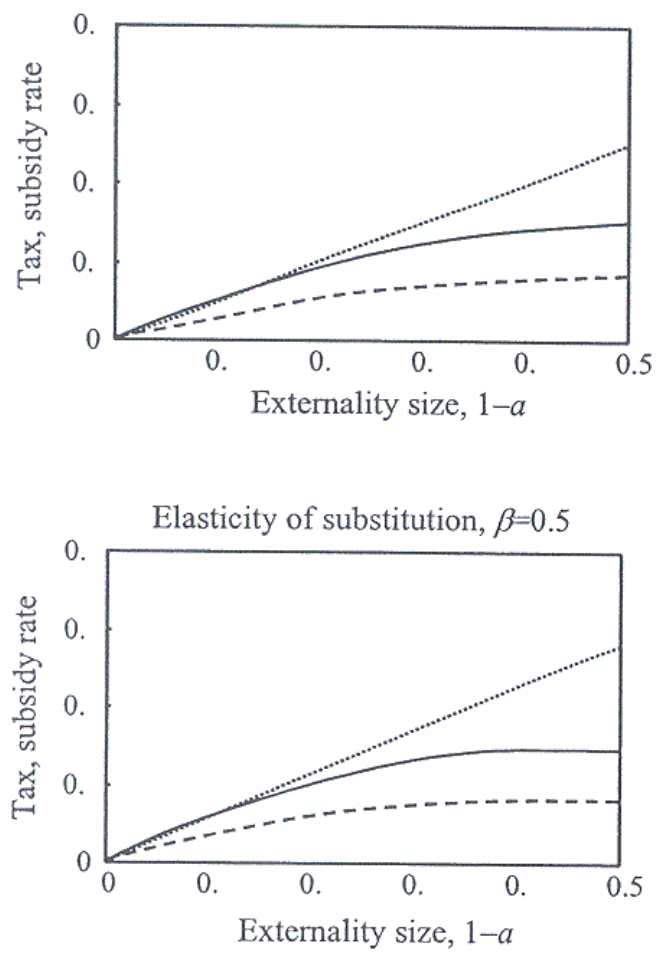

subsidy rate
Elasticity of substitution, $\beta=-0.25$

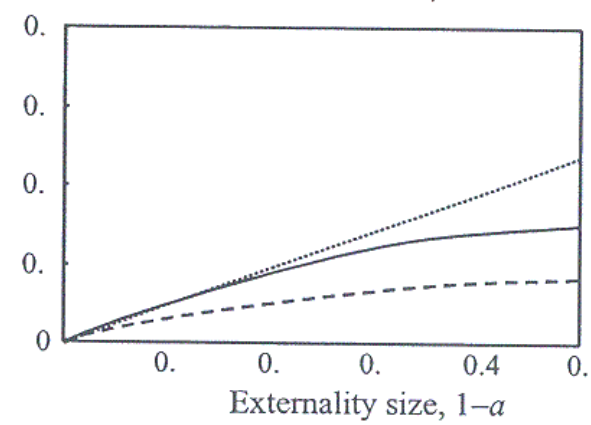

Elasticity of substitution, $\beta=0.25$

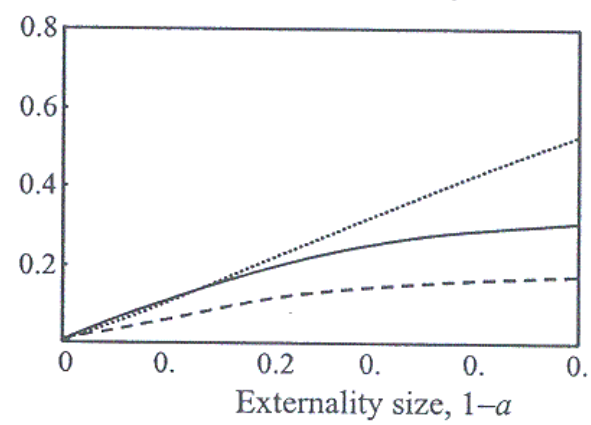

Elasticity of substitution, $\beta=1$

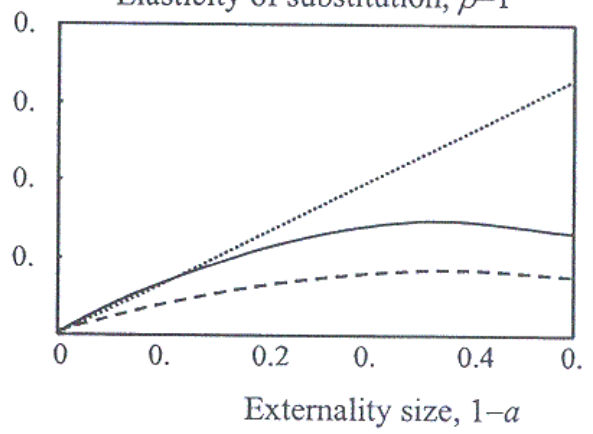

government size

Figure 1 shows that, in the absence of externalities, the optimal subsidy and tax rates are zero and therefore, government intervention is not required. However, as the externality 
increases (that is, $a$ decreases), the subsidy rate and, therefore, the government size, increase steadily to correct the external effect provoked by the average human capital in the production of goods. The tax rate on labor income also increases as the externality increases so as to finance the higher subsidy required to correct the externality. Since the subsidy and wage tax rates are of similar magnitude for mild external effects, as the external effects increase the wage tax required to finance, the optimal subsidy also increases. Note that the higher the externality, the lower the share of labor [that is, a lower value of $a$ in (4)] and therefore, the tax rate on labor income needed to finance the subsidy increases. Equation (15) shows that there is a negative relationship between the labor income tax and the subsidy rate. This explains why the increase in the subsidy rate slows down as the externality rises. Interestingly enough, these results remain roughly valid for alternative values of $\beta$, so that the elasticity of substitution between the share of effective labor devoted to the production of goods and the average human capital is relatively unimportant.

\section{Conclusions}

This paper develops an endogenous growth model with human capital in the UzawaLucas framework in which the average human capital has a positive external effect on the goods sector and output is produced with a CES technology. The paper provides conditions that guarantee the existence, uniqueness, and stability of equilibrium and also devises a fiscal policy capable of providing the required incentives to make the competitive equilibrium remain optimal. Physical capital income should be free of taxation. The optimal policy requires the use of a time-varying subsidy rate to the stock of human capital, which can be financed by means of a lump-sum tax combined with a constant tax on labor income, at least in the transitory phase. Lump-sum taxation is not needed to balance the government budget in the steady state. The simulation analysis shows that as the externality increases, the subsidy rate and therefore, the government size, increase steadily. The tax rate on labor income also increases as the externality increases to finance the higher subsidy required to correct the externality. However, the increase in the subsidy rate slows down as the externality rises because of the negative relationship between the subsidy and the wage tax.

\section{APPENDIX A}

Decentralized Economy

\section{Solution of the Decentralized Economy}

Let $J$ be the current value Hamiltonian of the household's utility maximization problem, and let $\lambda$ and $\mu$ be the multipliers for the constraints (3) and (2), respectively:

$J=\left(c^{1-\sigma}-1\right) /(1-\sigma)+\lambda\left[\left(1-\tau_{k}\right) r k+\left(1-\tau_{w}\right) w u h-c-T+\pi+s h\right]+\mu[\delta(1-u) h] \quad$.

The first order necessary conditions for an interior solution are:

$$
\begin{gathered}
c^{-\sigma}=\lambda, \\
\lambda\left(1-\tau_{w}\right) w h=\mu \delta h, \\
\dot{\lambda}=\left(\rho-\left(1-\tau_{k}\right) r\right) \lambda,
\end{gathered}
$$




$$
\left.\dot{\mu}=(p-\delta(1-u)) \mu-\lambda\left(1-\tau_{w}\right) w u+s\right) \quad,
$$

plus the usual transversality conditions:

$$
\lim _{t \rightarrow+\infty} \lambda k e^{-p t}=\lim _{t \rightarrow+\infty} \mu h e^{-p t}=0 .
$$

In what follows, the equilibrium condition $h=h_{a}$ will be imposed. From equation (A.3), using (5a), one can obtain the following expression:

$$
g_{\lambda}=\rho-\left(1-\tau_{k}\right)(1-\alpha) y / k
$$

Log-differentiating (A.1), the growth rate of consumption is then given by

$$
g_{c}=\left(1-\tau_{k}\right)(1-\alpha)(y / k) / \sigma-\rho / \sigma \quad .
$$

From (3), using the government's budget constraint (6), and the expressions for $r, w$, and $\pi$ in (5a)-(5c), the overall resources constraint of the economy can be obtained:

$$
g_{k}=y / k-c / k \quad .
$$

From equation (2), one can obtain the growth rate of human capital, $h$ :

$$
g_{h}=\delta(1-u)
$$

Using equations (A.2) and (5b) from (A.4), $g_{\mu}$ can be obtained as

$$
g_{\mu}=\rho-\delta-\frac{\delta s u\left(1-a+a u^{\beta}\right)}{a \alpha\left(1-\tau_{w}\right) u^{\beta}(y / h)} .
$$

Taking logarithms in (A.2), recalling (5b), and using (A.5), (A.7), (A.8), and (A.9), the growth rate of $u$ can be obtained as:

$$
\begin{aligned}
g_{u}= & \frac{\left(1-a+a u^{\beta}\right)}{(1-a)(1-\beta)+a u^{\beta}(1-\alpha)} *\left(\frac{s \delta u^{1-\beta}\left(1-a+a u^{\beta}\right)}{a \alpha\left(1-\tau_{w}\right)(y / h)}\right. \\
& \left.+\tau_{k}(1-\alpha)(y / k)-(1-\alpha)(c / k)-\frac{\dot{\tau}_{w}}{1-\tau_{w}}+(1-\alpha) \delta u+\delta \alpha\right) .
\end{aligned}
$$

The system (A.6), (A.7), (A.8), and (A.10) describes the dynamics of the market economy. Using these equations and the definitions $x=k / h$ and $q=c / k$, the system (7a)-(7c) can be obtained. 


\section{APPENDIX B}

Centrally Planned Economy

\section{First-Order Conditions of the Centrally Planned Economy}

Let $J$ be the current value Hamiltonian of the planner's maximization problem and $\lambda$ and $\mu$ be the multipliers for the constraints (8) and (2), respectively:

$$
J=\left(c^{1-\sigma}-1\right) /(1-\sigma)+\lambda\left[A k^{1-\alpha}\left(a(u h)^{\beta}+(1-a) h^{\beta}\right)^{\alpha / \beta}-c\right]+\mu \delta(1-u) h \quad .
$$

The first order necessary conditions for an interior solution are:

$$
\begin{gathered}
c^{-\sigma}=\lambda, \\
\lambda A \alpha a(k / h)^{1-\alpha} u^{\beta-1}\left(1-a+a u^{\beta}\right)^{-1+\alpha / \beta}=\mu \delta, \\
\dot{\lambda}=\rho \lambda-\lambda A(k / h)^{-\alpha}\left(1-a+a u^{\beta}\right)^{\alpha / \beta}(1-\alpha), \\
\dot{\mu}=\rho \mu-\delta(1-u) \mu-\lambda A(k / h)^{1-\alpha}\left(1-a+a u^{\beta}\right)^{\alpha / \beta} \alpha,
\end{gathered}
$$

plus the usual transversality conditions:

$$
\lim _{t \rightarrow+\infty} \lambda k e^{-p t}=\lim _{t \rightarrow+\infty} \mu h e^{-p t}=0
$$

Proof of Proposition 1

This section analyzes the conditions for the existence and uniqueness of an interior steady state for this economy. Equating (10b) and (11) to zero can produce (12a) and (12b) that yield the steady-state values of $q$ and $z$ as functions of the steady state value of $u$. Substituting the value of $q^{*}$ from (12a) into (10c) and equating the result to zero, either $1-a+a u^{* \beta}=0$ is obtained or equation (12c) is satisfied. Since the solution to $1-a+a u^{* \beta}=0$ is not feasible, $u^{*}$ must be given by the solution to (12c). Now, consider the function

$$
F(u)=(-1+a) \delta u^{1-\beta}+a(\rho+\delta(\sigma-1-\sigma u)) .
$$

Since $F^{\prime}(u)<0 \forall u \in(0,1)$, then $F(u)$ is a decreasing function. According to the Bolzano theorem, there exists $u^{*} \in(0,1)$ such that $F\left(u^{*}\right)=0$ if, and only if, the conditions $F(0)=a(\rho+\delta(\sigma-1))>0$ and $F(1)=-\delta+a \rho<0$ are verified. These conditions can be equivalently expressed as (14). Finally, the steady state of $x$ can be obtained from $z=A x^{-a}\left(1-a+a u^{* \beta}\right)^{1 / \beta}$ and $(12 \mathrm{~b})$ as

$$
x^{*}=A^{1 / \alpha}(1-\alpha)^{1 / \alpha}\left(\rho+\delta \sigma\left(1-u^{*}\right)\right)^{-1 / \alpha}\left(1-a+a u^{* \beta}\right)^{1 / \beta} .
$$

which is feasible if $u^{*} \in(0,1)$.

The transversality conditions can be easily shown to be satisfied if $0<u^{*}<1$. In fact, the first transversality condition, $\lim _{t \rightarrow+\infty} \lambda k e^{-\rho t}=0$, is equivalent to $g_{\lambda}^{*}+g_{k}^{*}-\rho<0$. Using (8), (B.3), (12a), and (12b), this expression is equivalent to $-\rho+\delta(1-\sigma)\left(1-u^{*}\right)<0$, 
which is negative if (14) is satisfied. The second transversality condition, $\lim _{t \rightarrow+\infty} \mu h e^{-p t}=0$, is equivalent to $g_{\mu}^{*}+g_{h}^{*}-\rho<0$. Using (2), (B.2), (B.4), (12a), and (12b), this expression is equivalent to $-\delta\left(u^{* 1-\beta}(1-a)+u^{*} a\right) / a<0$, which is negative if $0<u^{*}<1$. In summary, the authors have shown that (14) is a necessary and sufficient condition for the existence and uniqueness of an interior feasible steady state.

Proof of Proposition 2

Linearizing the system (10) around the steady state $\left(z^{*}, q^{*}, u^{*}\right)$ yields:

$$
\left(\begin{array}{c}
\dot{z} \\
\dot{q} \\
\dot{u}
\end{array}\right)=\left(\begin{array}{ccc}
-\alpha z^{*} & \frac{\alpha(1-\alpha)(1-\beta) z^{*}}{1-a-\beta+a \beta+a(1-\alpha) u^{* \beta}} & j_{13} \\
\frac{(1-\alpha-\sigma) q^{*}}{\sigma} & q^{*} & 0 \\
0 & \frac{(1-\alpha)\left(1+a\left(u^{\beta}-1\right)\right) u^{*}}{1-a-\beta+a \beta+a(1-\alpha) u^{* \beta}} & j_{33}
\end{array}\right)\left(\begin{array}{c}
z-z^{*} \\
q-q^{*} \\
u-u^{*}
\end{array}\right)
$$

where

$$
\begin{aligned}
& j_{13}=\frac{\alpha \beta(1-a) \delta-a u^{* \beta-1}\left((1-\alpha) z^{*}-\delta\right)}{1-a-\beta+a \beta+a(1-\alpha) u^{* \beta}} z^{*} \\
& j_{33}=\frac{\left(1-a+a u^{* \beta}\right)\left(\delta u^{*}+a\left(q^{*} u^{* \beta}(-1+\alpha) \beta-\left(u^{*}-\alpha \beta u^{* \beta}+(-1+\alpha)(1+\beta) u^{* 1+\beta}\right) \delta\right)\right)}{a\left(1-a-\beta+a \beta+a(1-\alpha) u^{* \beta}\right) u^{* \beta}}
\end{aligned}
$$

A sufficient condition for the local stability of system (10) is that the determinant of the coefficient matrix of (B.5) be negative and its trace be positive. After simplification, the trace of the coefficient matrix of (B.5) is obtained as:

$$
\begin{aligned}
t r= & \frac{\left.\left(1-a+a u^{* \beta}\right)(1-a) \delta u^{* 1-\beta}+\beta a\left(\delta(1-\sigma)-\rho+\delta \sigma u^{*}\right)+a u^{*} \delta(1-\alpha)\right)}{a\left((1-a)(1-\beta)+a(1-\alpha) u^{* \beta}\right) u^{* \beta}} \\
& +\left(\rho-\delta(1-\sigma)\left(1-u^{*}\right)\right)
\end{aligned}
$$

Now the paper proves that the trace is positive. First, using (14), the first term on the right hand side of the previous expression is positive. The denominator of the second term on the right hand side is positive as well. Equation (12c) can be expressed as:

$$
(1-a) \delta u^{* 1-\beta}+a\left(\delta(1-\sigma)-\rho+\delta \sigma u^{*}\right)=0,
$$

which entails that $a\left(\delta(1-\sigma)-\rho+\delta \sigma u^{*}\right)<0$. Then, the numerator of the second term on the right hand side, which is positive, is obtained since

$$
\begin{aligned}
(1-a) \delta u^{* 1-\beta}+\beta a\left(\delta(1-\sigma)-\rho+\delta \sigma u^{*}\right)+a u^{*} \delta(1-\alpha) & > \\
(1-a) \delta u^{* 1-\beta}+\beta a\left(\delta(1-\sigma)-\rho+\delta \sigma u^{*}\right) & > \\
(1-a) \delta u^{* 1-\beta}+a\left(\delta(1-\sigma)-\rho+\delta \sigma u^{*}\right) & =0
\end{aligned}
$$

Thus, it is proved that the trace is positive.

Next, the sign of the determinant of the coefficient matrix of (B.5) is calculated. Substituting for $q^{*}$ and $z^{*}$ from (12a) and (12b), the determinant is given by

$$
\begin{aligned}
\operatorname{det}= & -\frac{\left(1-a+a u^{* \beta}\right) \alpha\left(\rho+\delta \sigma\left(1-u^{*}\right)\right)\left(\rho-\delta(1-\alpha-\sigma)\left(1-u^{*}\right)\right)}{a(1-\alpha) \sigma\left((1-a)(1-\beta)+a(1-\alpha) u^{* \beta}\right.} \\
& \times\left((1-a) \delta u^{* 1-\beta}+\beta a\left(\delta(1-\sigma)-\rho+\delta \sigma u^{*}\right)+a u^{*} \delta(1-\alpha)\right)
\end{aligned}
$$


Now, the paper proves that the determinant is negative. The denominator of the previous expression is positive. The first and second factors of the previous expression are positive, the third factor is positive, since

$$
\begin{aligned}
\rho-\delta(1-\alpha-\sigma)\left(1-u^{*}\right) & =\rho+\delta \sigma\left(1-u^{*}\right)-\delta(1-\alpha)\left(1-u^{*}\right)> \\
\rho+\delta \sigma-\delta(1-\alpha)\left(1-u^{*}\right) & >\delta-\delta(1-\alpha)\left(1-u^{*}\right)>0
\end{aligned}
$$

where the second inequality holds from (12c), and the latter factor is positive, as has been shown in the previous analysis of the positiveness of the trace. Consequently, the determinant of the coefficient matrix of (B.5) is negative. Hence, the coefficient matrix of (B.5) must have one or three roots with negative real parts. Since the trace is positive, the coefficient matrix cannot have three roots with negative real parts, so it features one negative real root and two roots with positive real parts. This completes the proof.

\section{R eferences}

Benhabib, J.; Nishimura, K. "Indeterminacy and Sunspots with Constant Returns," Journal of Economic Theory, 81, 1998, pp. 58-96.

Bond, E. W.; Wang, P.; Yip, C. K. "A General Two-Sector Model of Endogenous Growth with Human and Physical Capital: Balanced Growth and Transitional Dynamics," Journal of Economic Theory, 68, 1996, pp. 149-73.

Caballé, J.; Santos, M. "On Endogenous Growth with Physical and Human Capital, Journal of Political Economy, 101, 1993, pp. 1042-67.

Chamley, C. P. "Externalities and Dynamics in Models of Learning or Doing," International Economic Review, 34, 1993, pp. 583-610.

Duffy, J.; Papageorgiou, C. "A Cross-Country Empirical Investigation of the Aggregate Production Function Specification," Journal of Economic Growth, 5, 2000, pp. 87-120.

García-Castrillo, P.; Sanso, M. "Human Capital and Optimal Policy in a Lucas-Type Model," Review of Economic Dynamics, 3, 2000, pp. 757-70.

Gómez, M. A. "Optimal Fiscal Policy in Uzawa-Lucas Model with Externalities," Economic Theory, 22, 2003, pp. 917-25.

-. "Optimality of the Competitive Equilibrium in the Uzawa-Lucas Model with Sector-Specific Externalities," Economic Theory, 23, 2004, pp. 941-48.

Jones, L. E.; Manuelli R. E. "A Convex Model of Equilibrium Growth: Theory and Policy Implications," Journal of Political Economy, 98, 1990, pp. 1008-38.

Ladrón-de-Guevara, A.; Ortigueira, S.; Santos, M. S. "A Two-Sector Model of Endogenous Growth with Leisure," Review of Economic Studies, 66, 1999, pp. 609-31.

Lucas, R. E., Jr. "On the Mechanics of Economic Development," Journal of Monetary Economics, 22, 1998, pp. 3-42.

—. "Supply-Side Economics: An Analytical Review," Oxford Economic Papers, 42, 1990, pp. 293316.

Mulligan, C. B.; Sala-i-Martín, X. "Transitional Dynamics in Two-Sector Models of Endogenous Growth," Quarterly Journal of Economics, 108, 1993, pp. 739-73.

Ortigueira, S. "A Dynamic Analysis of an Endogenous Growth Model With Leisure," Economic Theory, 16, 2000, pp. 46-62.

Pecorino, P. "The Growth Rate Effects of Tax Reform," Oxford Economic Papers, 46, 1994, pp. 492-501.

Pitchford, J. D. "Growth and the Elasticity of Substitution," Economic Review, 36, 1960, pp. 491504.

Rebelo, S. "Long-Run Policy Analysis and Long-Run Growth," Journal of Political Economy, 99, 1991, pp. 500-21. 
Solow, R. M. "A Skeptical Note on the Constancy of Relative Shares," American Economic Review, 48, 1958, pp. 618-31.

Uzawa, H. "Optimum Technical Change in an Aggregative Model of Economic Growth," International Economic Review, 6, 1965, pp. 18-31. 
Copyright of International Advances in Economic Research is the property of International Atlantic Economic Society and its content may not be copied or emailed to multiple sites or posted to a listserv without the copyright holder's express written permission. However, users may print, download, or email articles for individual use. 